\title{
Review of: "Does social trust stimulate university technology transfer? Evidence from China"
}

Ping Lei

Potential competing interests: The author(s) declared that no potential competing interests exist.

This paper examines the effect of social trust on university technology transfer and tests a mechanism that social trust facilitates university technology transfer by improving the level of university-industry cooperative innovation. The topic is interesting and the authors make a meaningful working. There are a few concerns with this study for the reference of the editor and the authors which include the following:

1. As for the only one hypothesis in this paper, it needs to be more specific.

2. The authors mentioned "There are a number of potential reasons why social trust can affect university technology transfer" and analysed two of them, and then pointed out that one of the two reasons couldn't be empirically tested for data availability. Although there is no logical mistake, it makes me feel that this study is not enough valuable.

3. The quantification of social trust index is of great significance. Besides the subjectivity of the questionnaire, as the authors said "if the provinces are in the top 10, the variable Trust1 equals 1; otherwise, it equals 0", how we distinguish the differences in social trust among these 10 provinces. Obviously, the work done in this part is not convincing. 